\title{
Development of the Third Generation JPL Electronic Nose for International Space Station Technology Demonstration
}

\author{
A. V. Shevade, M. L. Homer, H. Zhou, A. D. Jewell, A. K. Kisor, \\ K.S. Manatt, J. Torres, J. Soler, S.-P.S. Yen, and M. A. Ryan \\ Jet Propulsion Laboratory, California Institute of Technology
}

M. Blanco and W. A. Goddard, III Materials Simulation Center, California Institute of Technology

Copyright @ 2007 SAE International

\begin{abstract}
The capabilities of the JPL Electronic Nose have been expanded to include characteristics required for a Technology Demonstration schedule on the International Space Station (ISS) in 2008-2009 [1,2]. Concurrently, to accommodate specific needs on ISS, the processes, tools and analyses which influence all aspects of development of the device have also been expanded. The Third Generation ENose developed for this program uses two types of sensor substrates, newly developed inorganic and organic sensor materials, redesigned electronics, onboard near real-time data analysis and power and data interfaces specifically for ISS. This paper will discuss the Third Generation ENose with a focus on detection of mercury in the parts-per-billion range.
\end{abstract}

\section{INTRODUCTION}

The JPL Electronic Nose [3-7] is an event monitor designed and built for near real time air quality monitoring in crew habitat aboard the space shuttle/space station. This is an array-based sensing system which is designed to run continuously and to monitor for the presence of selected chemical species in the air at parts-per-million (ppm) to parts-per-billion (ppb) concentration ranges.

There have been three phases of development of the JPL Electronic Nose. In the first phase, a device capable of detecting, analyzing and quantifying ten analytes at the 1-hour Spacecraft Maximum Allowable Concentration (SMAC) was developed. This device was tested successfully in 1998 on Space Shuttle flight STS95 [6]. In the second phase, the ENose was miniaturized and the capabilities were significantly expanded to include 21 analytes and detection at varying humidity and temperature. This device, the
Second Generation ENose, was tested extensively on the ground, and was demonstrated to be able to detect, identify and quantify the 21 analytes at or below their 24hour SMACs [8]. The third phase of development is designed to monitor spacecraft cabin air quality in near real-time. In preparation for an upcoming, six-month technology demonstration aboard the International Space Station (ISS) in 2008-09, the JPL ENose team is developing a Third Generation ENose.

NASA has recently recognized a need to detect elemental mercury vapor in crew habitat in spacecraft. This is of concern because it is found in some lighting, and may be released if lights are broken or cracked. Detection of concentrations as low as single ppb $\mathrm{Hg}$ in breathing air is of great importance to the safety of astronauts.

Development of the Third Generation JPL ENose has required two major areas of development. One area is the design and fabrication of an interface

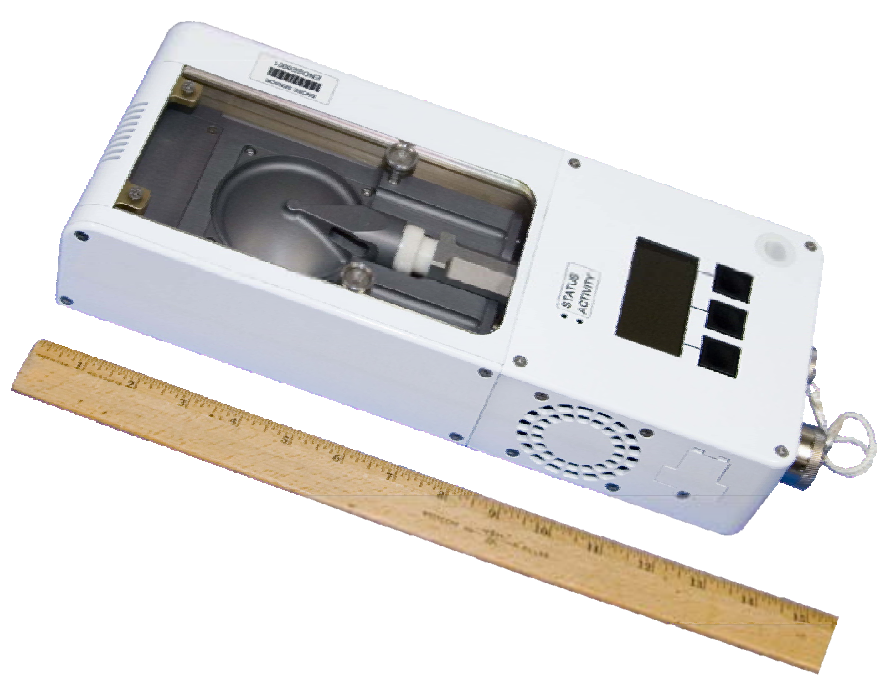

Figure 1: The Third Generation ENose. The Sensor Unit is enclosed in the Interface Unit, which will be connected to the ISS EXPRESS Rack 
unit which will allow the ENose to be operated through the EXPRESS Rack (EXpedite The PRocessing Of Experiments To Space Station) on the ISS for a sixmonth technology demonstration experiment. In the other area, the capabilities of the sensing platform, the Second Generation ENose, including sensing materials, sensor substrate, and data analysis routines are being expanded in order to include the ability to detect additional inorganic species, mercury and sulfur dioxide, and to provide quasi-real time data analysis with readout.

This paper will focus on the development and performance of organic and inorganic sensing materials to be used in the Third Generation ENose for $\mathrm{Hg}$ detection under a variety of environmental conditions.

\section{DEVELOPMENT OF THE THIRD GENERATION JPL ENOSE}

The Third Generation ENose is a modified Second Generation ENose Sensor Unit coupled with an Interface Unit, as shown in Figure 1. The Interface Unit is designed and built by Oceaneering Space Systems (OSS). The ENose Interface Unit fully encloses ENose Sensor Unit and provides power conditioning and distribution, thermal management and a display. It also includes computers for device control, data acquisition and data analysis and interfaces directly with the EXPRESS Rack for power and for data transfer.

The ENose Interface Unit receives power from the EXPRESS Rack (28 V) and converts the power from the ISS into voltages compatible with interface unit computer systems and functions as well as the electronic and pneumatic systems of the ENose Sensor Unit. The computers in the Interface Unit manage data collection, data storage and data analysis for the ENose. The display on the Interface Unit may be configured to display results of data analysis, although in the experimental phase, data analysis will not be shown. Raw data as well as processed data and analysis results will be downlinked from the ENose through the EXPRESS Rack communications system. The Interface Unit also controls the thermal environment of the ENose Sensor Unit.

The ENose Sensor Unit consists of an anodized aluminum chassis which houses the sensor array and pneumatic system. The ENose Sensor Unit also contains the electronics to route power, relay data and commands between the sensor array and the ENose Interface Unit. The Sensor Unit for the Third Generation ENose is designed and built by JPL; it is based on the platform developed as the Second Generation JPL ENose, which has previously been discussed in detail [1, 7].

Briefly, the sensor unit monitors the environment by pumping air from the surroundings into the sensor chamber, where the response of a sensing array is read. The air is directed either through a glass bead filter which serves as a particle filter and which is in line to provide a pressure drop equal to that in the charcoal filter, and an activated charcoal filter which is put in line to provide cleaned air for baseline data. A solenoid valve is programmed to open the path to the charcoal filter and provide clean airflow for a programmable period of time at programmable time intervals; otherwise, the air is directed through the glass beads. When air enters the sensing chamber, resistance of each element in a 32sensor array is measured. A baseline of clean air is established, and deviations from that baseline are recorded as changes in resistance of the sensors. The pattern of distributed response of the sensors is deconvoluted, and chemical species to which the device has been trained are identified and quantified by using a set of software analysis routines developed for this purpose. A block diagram of the Third Generation ENose (Interface Unit plus Sensor Unit connected to the

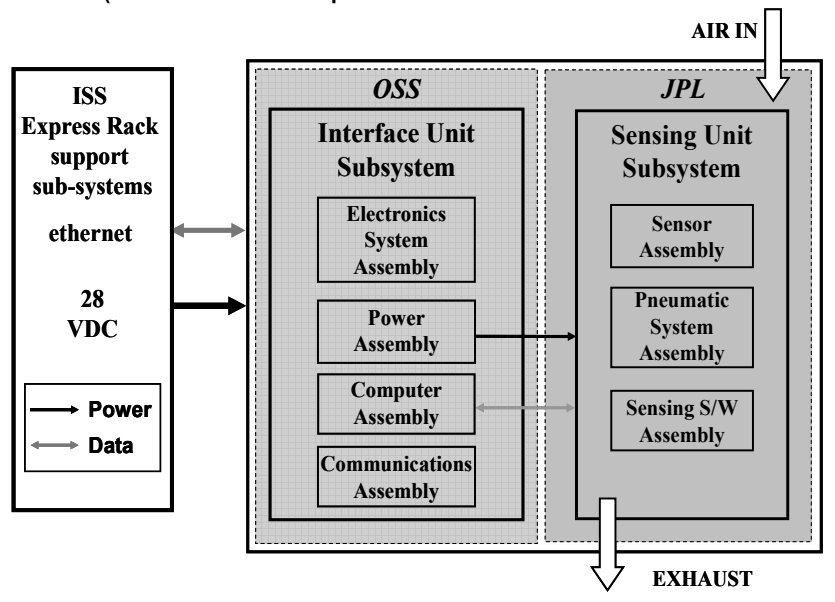

Figure 2: Block diagram of the $3^{\text {rd }}$ Generation ENose.

EXPRESS Rack) is shown in Figure 2.

In previous versions of the JPL ENose, sensors in the 32 element sensing array were made from polymer-carbon composite sensing films [1-7] and deposited $2 \mathrm{~mm} \times 1$ $\mathrm{mm} \mathrm{Pd-Au} \mathrm{electrode} \mathrm{sets,} \mathrm{where} \mathrm{electrode} \mathrm{spacing} \mathrm{is}$ approximately $250 \mu \mathrm{m}$. Polymer deposition and the electrode sets have previously been discussed in detail $[6,7,9]$. In order to detect elemental $\mathrm{Hg}$ vapor, it has been necessary to develop alternative sensing materials as well as alternative sensor substrates. The substrates developed have been designed to fit into the Sensor Unit platform with no changes to the Sensor Unit enclosure and minimal changes to the electronics. Materials have been developed specifically to respond to $\mathrm{Hg}$ vapor.

The sensor substrates developed for use with materials to detect $\mathrm{Hg}$ are microhotplates, which allow sensing and regeneration of the sensor to take place at temperatures ranging from environmental temperature $\left(20-25^{\circ} \mathrm{C}\right)$ up to $200^{\circ} \mathrm{C}$. Microhotplate substrates were selected in order to minimize the power requirements of heating the sensors. 
As a first step in selection of materials to detect elemental $\mathrm{Hg}$ vapor, a literature search was done to determine what had previously been used [1]. It was clear from that search that while there were some developmental materials, metallic gold films are the most reliable method of detecting mercury vapor [10].

We have used several modeling approaches to screen materials for use in the JPL ENose, and we have modeled the interaction energies of analytes with polymers using molecular dynamics [11]. These interaction energies are used in semi-empirical models developed using Quantitative Structural Activity Relationships [12] to predict whether particular polymers will respond to the presence of particular analytes with a change in resistance in a polymer-carbon composite sensing film [12]. QSAR studies did not predict any response to $\mathrm{Hg}$ from polymers which had previously been used as sensing materials in the JPL ENose.

A second modeling approach, based on quantum mechanical techniques, was developed to model the interaction energies of analytes and functional groups present on polymers [13]. Both inorganic and organic materials were investigated as sensing materials for $\mathrm{Hg}$. This modeling technique predicted that polymers containing amines could respond to $\mathrm{Hg}$ vapor. The model and its technique is discussed in detail elsewhere [14] and briefly below.

\section{MODEL OF SENSOR-ANALYTE RESPONSE}

A first principles, quantum mechanical model was used to predict the strength of interactions between $\mathrm{Hg}$ and organic molecules. This methodology involves calculating interaction energies for organic- $\mathrm{Hg}$ binary systems, using Jaguar 6.5 [14]. Common classes of organic structures are considered as functionalities which may be found on polymer chains. The calculations undertaken include interaction energies of alkanes, alkenes, aromatics, amines (primary and secondary), aldehydes, and carboxylic acids with sulfur dioxide. Interaction energies are calculated using B3LYP flavor of Density Functional Theory (DFT). These quantum mechanical results are used to develop a first principles force field for use in the calculation of binding (or interaction) energies $\left(\mathrm{E}_{\text {bind }}\right)$ of $\mathrm{Hg}$ atoms with various functionalities which represent polymers [15-17]. Only interaction energies less than zero (exothermic reactions) will result in binding between analyte and functional group such that there it may result in a change in resistance in a polymer-carbon composite film; strong binding energies are on the order of $10 \mathrm{kcal} / \mathrm{mole}$.

Results of modeled interaction energies of organic- $\mathrm{Hg}$ systems indicate that a polymer candidate for $\mathrm{Hg}$ detection would be one containing amine functional groups, preferably primary or secondary. An example of interaction energy calculations is shown in Figure 3, where $\mathrm{E}_{\text {bind }}$ is weak, $\sim-0.4 \mathrm{kcal} / \mathrm{mole}$; this would lead us to expect that a polymer carbon composite sensor made from an $1^{\circ}$ or $2^{\circ}$ amine containing polymer would show a weak response to the presence of vapor phase mercury. No binding was shown for other functional groups

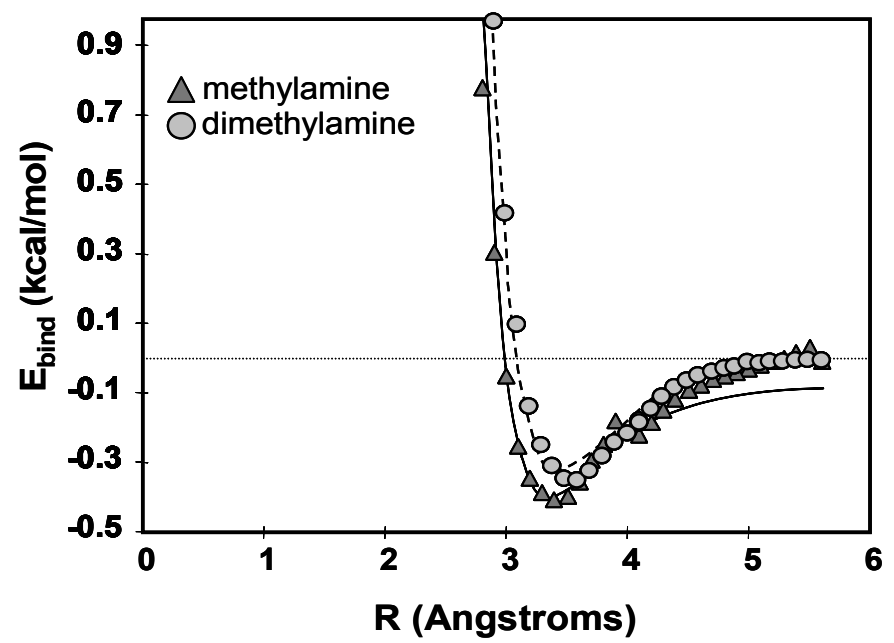

Figure 3: Modeled binding energy of $\mathrm{Hg}$ with amines. Triangles are calculated binding energy of $\mathrm{Hg}$ with methylamine; circles dimthyl $\left(2^{\circ}\right)$ amine. Lines are Morse potentials calculated separately.

modeled.

\section{MATERIALS SELECTED FOR TESTING}

Quantum mechanical modeling suggests that aminecontaining polymers may be used to detect $\mathrm{Hg}$. Such polymers have been developed for $\mathrm{SO}_{2}$ sensing $[2,18]$, and were tested as mercury sensors. Modeling indicates that other polymer candidates should have very weak or no response to $\mathrm{Hg}$, and no additional polymers were selected as potential $\mathrm{Hg}$ sensors; however, polymer-carbon composite films selected for the array were tested for $\mathrm{Hg}$ response.

Previous work in development of sensors for $\mathrm{Hg}$ detection by other researchers have predominately focused on using thin films of gold and other noble metals to form a metal-mercury amalgam, and reading the change in resistance with amalgam formation [10, 19-27]. In addition, palladium chloride with tetrahydroxyethyl-ethylenediamine (THEED) has been used in one study of $\mathrm{Hg}$ sensing [28]. Inorganic material candidates selected for testing for $\mathrm{Hg}$ sensing include gold films, gold sputtered on polymer films and $\mathrm{PdCl}_{2}$ films. Performance of these materials as sensors for elemental mercury vapor is discussed below. 


\section{PERFORMANCE OF THIRD GENERATION SENSORS FOR MERCURY DETECTION}

The objective of this work was to design, synthesize and select sensing materials able to detect $\mathrm{Hg}$ in humidified air at $3 \mathrm{ppb}$, as required by NASA for this Technology Demonstration, and that can be integrated into the existing JPL ENose sensor unit platform with an operating temperature of $20-32^{\circ} \mathrm{C}$ and a regeneration temperature up to $200^{\circ} \mathrm{C}$.

Gold film sensing for vapor phase elemental mercury is the standard technique used in laboratory and field work. Gold films are sufficiently sensitive for NASA's application, but require temperatures as high as $200^{\circ} \mathrm{C}$ for several minutes in a flow of clean air for regeneration [20]. They have been selected as sensor elements for the Third Generation ENose. The high temperature required for regeneration will be provided by microhotplates embedded under the sensors with gold films. However, the ENose program desires dissimilar redundancy in sensing materials for $\mathrm{Hg}$ detection, alternate sensing materials were investigated along with evaporated gold films.

In the current investigation, we considered and tested several sensing materials for $\mathrm{Hg}$ detection, including gold films, treated gold films, sintered palladium chloride $\left(\mathrm{PdCl}_{2}\right)$ thick films, polymer-carbon composite thick films, and thin gold films on polymer-carbon composites. All materials were tested in flowing, humidified air at 20$25^{\circ} \mathrm{C}$. Relative humidity in all tests was $\sim 30 \%$.

\section{GOLD FILM SENSORS}

Initial studies of $\mathrm{Hg}$ sensing focused on repeating the well-known ability of thin gold films to amalgamate $\mathrm{Hg}$, resulting in a decrease in conductivity in the film [10]. Studies showed that these films showed sufficient change in conductivity and could be integrated into the JPL ENose sensor unit platform if the films were made $\sim 15 \mathrm{~nm}$ thick. With a NASA goal of keeping power utilization at a minimum, and the need to regenerate

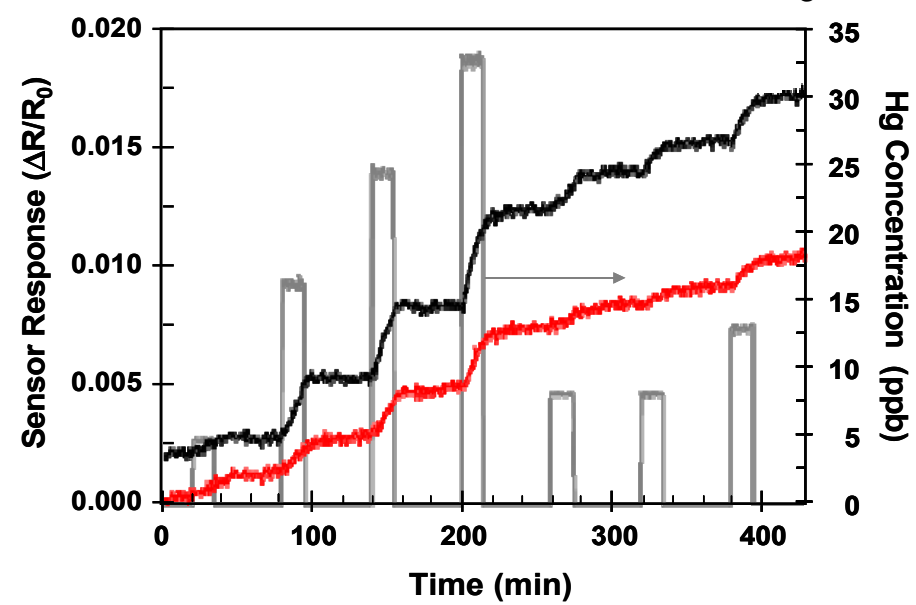

Figure 4: Response of two abraded gold films on ENose substrates to $\mathrm{Hg}$ vapor. Light, rectangular traces are $\mathrm{Hg}$ delivery concentrations. gold films at temperatures well in excess of $40^{\circ} \mathrm{C}$, these sensors can be made only on microhotplate sensors. Thus, two microhotplate locations were reserved for gold films.

The response of gold sensing films deposited on JPL ENose substrates and treated after deposition was also evaluated. The gold films were vacuum deposited, then treated by physical abrasion by grit blasting, where abrasive particles are accelerated in air and forcefully directed against the gold films. The high speed abrasive particles thin and roughen films; the films then exhibit greater surface area as compared to the sputtered gold film initially deposited. As seen in Figure 4, the abraded gold films show good sensitivity to mercury in the ppb range, but do not regenerate in air at room temperature. Such films may be used as a dosimeter, but must be regenerated at high temperature or replaced after they no longer respond to $\mathrm{Hg}$. It can also be seen that the sensing response of abraded gold films is repeatable for a single film, and that the magnitude of response may be used to determine mercury concentration, but the films are not reproducible. This lack of reproducibility from sensor to sensor may be attributed to the challenges involved in obtaining similar films through the abrasion technique. This lack of reproducibility eliminated gold films treated with abrasion from consideration for this application.

\section{PALLADIUM CHLORIDE SENSORS}

Palladium chloride has been used as a component in polymer-metal composite films used for $\mathrm{Hg}$ detection [28]. That study found that a coating which was $50 \%$ $\mathrm{PdCl}_{2}$ was the optimum preparation for detection of $\mathrm{Hg}$ in the single ppm range. Reasoning that the polymer acted primarily as a carrier for $\mathrm{PdCl}_{2}$, we chose to study sintered thick films of $\mathrm{PdCl}_{2}$ for mercury vapor sensing. Palladium chloride sensing films were formulated by preparing an aqueous solution of $\mathrm{PdCl}_{2}$ solution followed by solution casting and thermal curing on microhotplate sensor substrates. The films were sintered in air at $425^{\circ} \mathrm{C}$.

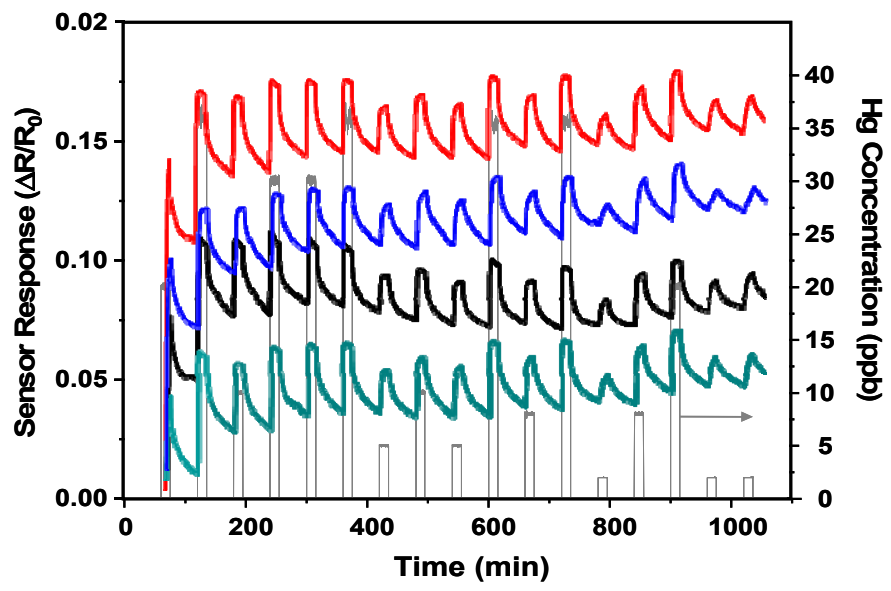

Figure 5: Response of four sintered $\mathrm{PdCl}_{2}$ sensors to $\mathrm{Hg}$ vapor in air. Light, rectangular traces are $\mathrm{Hg}$ delivery concentrations. 
As seen in Figure 5, $\mathrm{PdCl}_{2}$ sensing films (s1, s2, s3, s4) show good sensitivity and reproducibility of response to $\mathrm{Hg}$ concentrations of $2-10 \mathrm{ppb}$ at $23^{\circ} \mathrm{C}$ in humidified air. $\mathrm{PdCl}_{2}$ sensor response magnitude does not increase above $10 \mathrm{ppb} \mathrm{Hg}$. These sensing films also show partial regeneration under mild conditions, temperatures $\angle 40^{\circ} \mathrm{C}$, and good repeatability of response for concentrations $10 \mathrm{ppb}$ and under.

The initial exposure of $\mathrm{PdCl}_{2}$ films to $\mathrm{Hg}$ vapor of any concentration results in responses about one order of magnitude greater than subsequent exposures (initial baseline not shown in Figure 5.) The sensors may be regenerated by heating at elevated temperatures in flowing clean air for several minutes.

Figure 6 shows the results of repeated delivery of $\mathrm{Hg}$ vapor in humidified air ( $30 \%$ relative humidity) at $23^{\circ} \mathrm{C}$ on $\mathrm{PdCl}_{2}$ sensors. Sensor response is linear with concentration up to $10 \mathrm{ppb}$ if the initial response points are removed from consideration. At concentrations above $10 \mathrm{ppb}$, the magnitude of sensor response to $\mathrm{Hg}$ does not increase. Initial response magnitudes are also linear with concentration up to $10 \mathrm{ppb}$. In operation, $\mathrm{PdCl}_{2}$ sensors will have been exposed to $\mathrm{Hg}$ vapor before the device is turned on, so it will not be necessary to make a distinction between initial and subsequent responses. The sensors may be regenerated at elevated temperature. Alternatively, $\mathrm{PdCl}_{2}$ sensors may be exposed to $\mathrm{Hg}$ in advance of their use and not regenerated, to keep responses linear and repeatable over the $0-10 \mathrm{ppb}$ range.

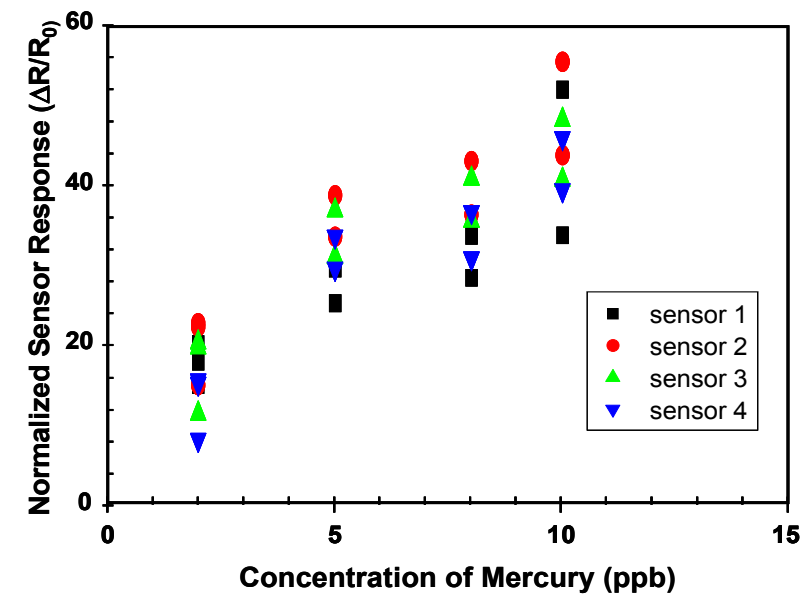

Figure 6: Repeated delivery of $\mathrm{Hg}$ vapor to four identical $\mathrm{PdCl}_{2}$ sensors at various concentrations.

\section{POLYMER-CARBON COMPOSITE SENSORS}

\section{Response of Modeled Polymer Sensors}

Based on the results of modeled quantum mechanical binding energy between mercury and organic ligands, two polymers were selected and made into polymercarbon black composite sensors. These two polymers EYN1 and EYN2 [1] are both poly-4-vinyl pyridine derivatives with a quaternary and a primary amine, and have also been used for detection of $\mathrm{SO}_{2}[2,18]$. The polymers were synthesized from poly-4-vinyl pyridine and made into polymer-carbon composite sensing films using protocols which have been previously described $[6,7]$. These films were loaded with $10-15 \%$ carbon by weight and solution cast onto microhotplate sensor substrates and onto ENose substrates. It was expected from the small magnitude of the binding energy that any response of sensors made from these polymers would be weak, as the binding energy is on the order of -0.3 $\mathrm{kcal} / \mathrm{mole}$, whereas the binding energy for these polymers with $\mathrm{SO}_{2}$ is on the order of $-10 \mathrm{kcal} / \mathrm{mole}[2$, 18].

As shown in Figure 7, polymer EYN1, with a primary and quaternary amine in its structure, has a weak response to mercury vapor at concentrations of $30 \mathrm{ppb}$ and higher. the three traces in the figure are sensors made with different loads of carbon black for conduction; $15 \%(\mathrm{w} / \mathrm{w})$ carbon black (red) has the largest response, while 10\% (green) and $12 \%$ (blue) loads have smaller responses. In any case, the level of response found in this polymercarbon composite sensors is not suitable for a mercury sensor at these concentrations, and so this sensing material cannot be used in the third Generation Electronic Nose. However, the response is validation of

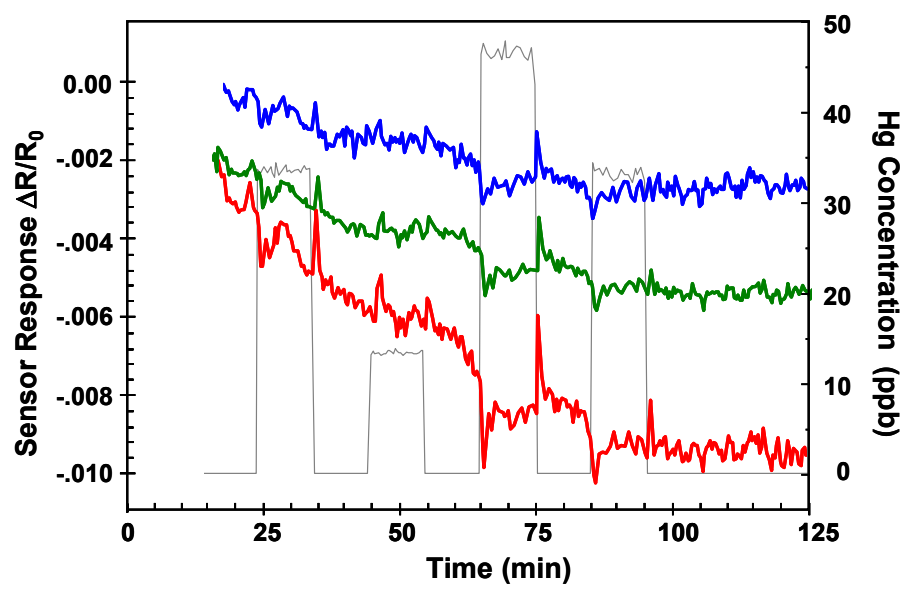

Figure 7: Response of three sensors made from polymer EYN1 to $\mathrm{Hg}$ in air. Light, rectangular traces are $\mathrm{Hg}$ delivery concentrations.

the results of the modeled response. Further work and optimization would be necessary to use these materials as mercury sensors at higher concentrations.

\section{$\underline{\text { Response of } 1^{\text {st }} \text { and } 2^{\text {nd }} \text { Generation Polymer Sensors }}$}

Polymers used in the first and second generation JPL ENose were also tested for response to $\mathrm{Hg}$ in humidified air. As expected, based on both QSAR and quantum mechanical modeled results, these polymers did not 
respond to the presence of $\mathrm{Hg}$ in the $\mathrm{ppb}$ range. Imide, amide and amine containing polymers showed very weak response at $\mathrm{Hg}$ concentrations well above the required range.

\section{GOLD FILMS ON POLYMER SENSORS}

A novel approach to combining the sensing functionalities of polymer-carbon composite films and gold films to achieve both mercury and other analyte detection is to deposit a thin layer of gold on a polymercarbon composite film. In this study, we investigated sensing capabilities of several polymers with a $10 \mathrm{~nm}$ gold film vacuum deposited on top of the polymer film. As seen in Figure 8, there is strong reproducible, recoverable response to mercury in the $\mathrm{ppb}$ concentration range.

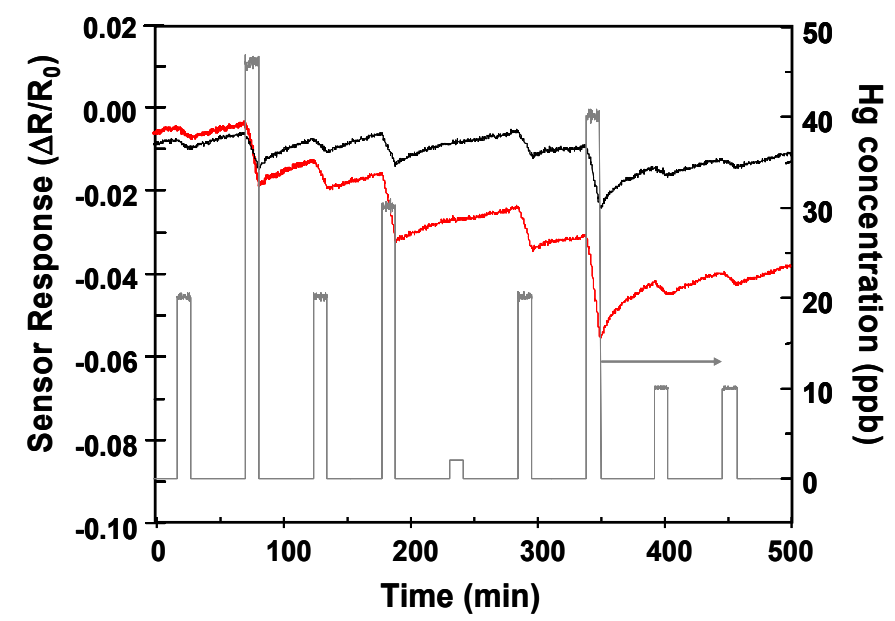

Figure 8: Response of two sensors made of gold film deposited on poly(caprolactone) polymer-carbon composite films to mercury in air at room temperature. Light rectangular traces are Ho deliverv conncentrations

Electron microscopy studies of the sensors shows that the gold is distributed as partially interconnected islands across the polymer-carbon composite film. This distribution of gold as islands allows the polymer to respond to organic vapors in the usual manner, by sorption into the polymer and swelling, to reduce conductivity, but also allows $\mathrm{Hg}$ to amalgamate with gold and influence the overall conductivity of the film. Some gold will penetrate beyond the surface of the polymer film, and $\mathrm{Hg}$ atoms or vapors of other targeted species may enter the polymer matrix and cause a change in the resistance of the film, either because of swelling in the matrix [29] or because of changes caused to the conductive medium, such as through amalgamation or sorption. These films do not need to be used on microhotplate sensors, as they regenerate sufficiently at moderate temperatures for use.

\section{CONCLUSIONS}

We have developed and tested several novel organic and inorganic sensing materials to detect vapor phase, elemental mercury at ppb concentration levels at room temperature. Sensing materials tested include thin gold films, treated gold films, $\mathrm{PdCl}_{2}$, polymer-carbon composites and gold sputtered on polymer. These materials have been tested successfully (operated and regenerated), and selections for inclusion into the Third Generation Electronic Nose Technology Demonstration have been made.

Materials which showed good response to mercury vapor but which will not be used in the Third Generation ENose include abraded gold films and gold-on-polymer films. Abraded gold films require further work to make the response reproducible. Gold-on-polymer films have excellent response to mercury vapor, and were initially selected for inclusion in the Third Generation ENose, but it was found that there was not sufficient batch-to-batch reproducibility in these films to include them in the ENose sensing array now. Further work is required to determine how to control the batch characteristics.

The two materials selected for inclusion into this Technology Demonstration are thin gold films, the standard material for vapor phase $\mathrm{Hg}$ detection, and sintered $\mathrm{PdCl}_{2}$ thick films. This is the first report of using sintered $\mathrm{PdCl}_{2}$ as a sensing material for $\mathrm{Hg}$. With these two materials, the Third Generation ENose includes dissimilar redundancy for $\mathrm{Hg}$ detection. Neither of these materials shows significant response to other analytes selected for this Technology Demonstration. In addition, amine containing polymers selected for $\mathrm{SO}_{2}$ detection will show minor response to $\mathrm{Hg}$, and may be used to follow clean up processes if there is high concentration of mercury released into the air by a containment failure.

\section{ACKNOWLEDGMENTS}

The research reported in this paper was carried out at the Jet Propulsion Laboratory, California Institute of Technology under a contract with the National Aeronautics and Space Administration and supported by the Advanced Environmental Monitoring and Control Program, ESMD, NASA.

\section{REFERENCES}

1. M.A. Ryan, M.L. Homer, H. Zhou, K. Manatt, A. Manfreda, A. Kisor, A. Shevade and S.P.S. Yen; "Expanding the Analyte Set of the JPL Electronic Nose to Include Inorganic Species;" Journal of Aerospace, SAE Transactions, 2005-01-2880 (2005).

2. M.A. Ryan, M.L. Homer, H. Zhou, K. Manatt, A. Manfreda, A. Kisor, A. Shevade and S.P.S. Yen; 
"Expanding the Capabilities of the JPL Electronic Nose for an International Space Station Technology Demonstration", Proc. $36^{\text {th }}$ Intl. Conf. on Environ. Systems, SAE, 2179 (2006).

3. M.A. Ryan, M.L. Homer, M.G. Buehler, K.S. Manatt, F. Zee, and J. Graf, "Monitoring the Air Quality in a Closed Chamber Using an Electronic Nose," Proc. 27th Intl. Conf. on Environ. Systems, SAE (1997).

4. M.A. Ryan, M.L. Homer, M.G. Buehler, K.S. Manatt, B. Lau, D. Karmon, and S. Jackson, "Monitoring Space Shuttle Air for Selected Contaminants Using an Electronic Nose," Proc. 28th Intl. Conf. on Environ. Systems, SAE (1998).

5. M.A. Ryan, M. L. Homer, H. Zhou, K. S. Manatt, V. S. Ryan, and S. Jackson, "Operation of an Electronic Nose Aboard the Space Shuttle and Directions for Research for a Second Generation Device," Proc. 3oth Intl. Conf. on Environ. Systems, SAE (2000).

6. M.A. Ryan, H. Zhou, M.G. Buehler, K.S. Manatt, V.S. Mowrey, S.P. Jackson, A.K. Kisor, A.V. Shevade, and M.L. Homer, "Monitoring Space Shuttle Air Quality Using the JPL Electronic Nose," IEEE Sensors Journal, 4, 337 (2004).

7. M.A. Ryan, A.V. Shevade, H. Zhou and M.L. Homer, "Polymer-Carbon-Composite Sensors for an Electronic Nose Air Quality Monitor," MRS Bulletin, 29, 714 (2004).

8. Spacecraft Maximum Allowable Concentrations for Selected Airborne Contaminants, vols.1 \& 2, National Academy Press, Washington DC, 1994.

9. M. A. Ryan, M. L. Homer, H. Zhou, K. Manatt and A. Manfreda, "Toward A Second Generation Electronic Nose at JPL: Sensing Film Optimization Studies;" Proc. 31st Int'l. Conf. Environ. Systems, SAE, 2308 (2001).

10. J.J. McNerney, P.R. Busek and R.C. Hanson, "Mercury detection by means of thin gold films," Science, 178, 611 (1972).

11. A.V. Shevade, M.A. Ryan, M.L. Homer, A.M. Manfreda, H. Zhou, K.S. Manatt, "Molecular Modeling of Polymer Composite-Analyte Interactions in Electronic Nose Sensors," Sens. \& Act. B, 93, 84 (2003).

12. A.V. Shevade, M.A. Ryan, M.L. Homer, A.M. Manfreda, H. Zhou and K. Manatt, "Correlating Polymer-Carbon Composite Sensor Response with Molecular Descriptors," J. Electrochem. Soc., 153, H209 (2006).

13. M. Blanco, A.V. Shevade, M.A. Ryan, M. L. Homer, W. A. Goddard, "Elemental Mercury Interactions with Organic Compounds: A DFT Study," J. Phys. Chem. $B$ (in preparation).

14. Jaguar, version 6.5, Schrodinger, LLC, New York, NY (2005).

15. A. D. Becke; "Density-Functional Thermochemistry 3. The Role Of Exact Exchange," J. Chem. Phys., 98, 5648 (1993).

16. C. Lee, W. Yang, and R.G. Parr; "Development of the Colle-Salvetti Correlation-Energy Formula into a
Functional of the Electron-Density," Phys. Rev. B, 37, 785(1998).

17. X. Xin and W. A. Goddard III; "The X3LYP extended density functional for accurate descriptions of nonbond interactions, spin states, and thermochemical properties;" Proc. Nat. Acad. Sci., 101, 2673 (2004).

18. A.V. Shevade, M. Blanco, M.A. Ryan, M. L. Homer, W. A. Goddard, "Identifying Chemical Functionalities in Polymers to Detect Sulfur Dioxide (SO2) using Quantum Mechanics," J. Phys. Chem. B (in preparation).

19. Q. Bristow, "An evaluation of the quartz crystal microbalance as a mercury vapor sensor for soil gases," J. Geochem. Expt., 1, 55 (1972).

20. B. Mazzolai, V. Mattoli, V. Raffa, G. Tripoli, D. Accoto, A. Menciassi and P. Dario, "A microfabricated physical sensor of atmospheric mercury monitoring," Sens. \& Act. A, 113, 282 (2004).

21. T. Thundat, E.A. Wachter, S.L. Sharp and R.J. Warmack, "Detection of $\mathrm{Hg}$ Vapor Using Resonating Microcantilevers," App. Phys. Lett., 66, 1695 (1995).

22. J.J. Caron, R.B. Haskell, P. Benoit, J.F. Vetelino, "Surface Acoustic Wave Mercury Vapor Sensor," IEEE Trans. Ultrasonics Ferroelectrics and Freq. Control, 45, 1393 (1998).

23. C.L. Britton, R.L. Jones, P.I. Oden, Z. Hu, R.J. Warmack, S.F. Smith, W.L. Bryan, and J.M. Rochelle, "Multiple-Input Microcantilever Sensors," Ultramicroscopy, 82, 17 (2000).

24. B. Rogers, L. Manning, M. Jones, T. Sulchek, K. Murray, B. Beneschott, J.D. Adams, Z. Hu, T. Thundat, H. Cavazos, and S.C. Minne, "Mercury Vapor Detection With a Self-Sensing, Resonating Piezoelectric Cantilever," Rev. Sci. Inst., 74, 4899 (2003).

25. F.L. Fertonani, E. Milare, A.V. Benedetti and M. Ionashiro, "Solid State Reactions of Mercury with Pure Noble Metals, Part 2,"J. Thermal Anal. and Cal, 67, 403 (2002).

26. E. Milare, F.L. Fertonani, A.V. Benedetti and M. Ionashiro, "Contribution to the Study of the SolidState Reaction of Mercury With Pure Rhodium," J. Thermal Anal. and Cal., 59, 617 (2000).

27. F.L. Fertonani, A.V. Benedetti and M. Ionashiro, "Contribution to the Study of the Reaction of Mercury With Platinum and a Platinum-Iridium Alloy," Thermochim. Acta, 265, 151 (1995).

28. D. P. Ruys, J. F. Andrade and O.M. Guimaraes, "Hg Detection in Air Using a Coated Piezoelectric Sensor," Anal. Chim. Acta, 404, 95 (2000).

29. E.J. Severin and N.S. Lewis, "Relationship among resonant frequency changes on a coated quartz crystal microbalance, thickness change, and resistance responses of polymer-carbon black composite chemiresistors;" Anal. Chem. 72, 2008 (2000). 


\section{CONTACT}

Dr. M. A. Ryan

MS 184-105; Jet Propulsion Laboratory

California Institute of Technology

4800 Oak Grove Drive

Pasadena CA 91109

tel: (818) 354-8028

email: mryan@jpl.nasa.gov 